\title{
Smartphones and Exploitation in the Age of Digital Capitalism: Ordinary Aspects of the Transformation of Everyday Life
}

\author{
Emre Canpolat
}

Hacettepe University, Ankara, Turkey, canemrepolat@gmail.com

\begin{abstract}
This study examines the transformation of everyday life through smartphones, focusing on the daily experiences of smartphone users in Turkey. With their multimedia features, smartphones (defined as a "melting pot" from the technological perspective or polymedia and metamedia in a broader sense) take an important place in users' everyday lives. As these features and the services accessible through smartphones are offered in commodity form, they inevitably result in the exploitation of users' labour, the commodification of user data, the shifting of paid work into 'leisure time', and finally the transformation of everyday life through smartphones. The main argument of this study is that, under these social conditions, smartphones, referred to as "a melting pot" from the technological perspective, turn into a melting pot of exploitation, and their users experience these interactions not as direct economic relations but as routine social relations.
\end{abstract}

Keywords: smartphone, everyday life, social media, exploitation, commodity form

\section{Introduction}

A cellular telephone is considered a smartphone if it has features that standard phones lack such as Internet access, built-in and downloadable applications, computer-like capacities, and a touchscreen with a high resolution (Woyke 2014, 10; Hsiao and Chen $2015,158)$. The integration and the digital infrastructure at different levels entail the unity of software and hardware components, comprising the 'smart' feature of smartphones. While explaining his smartphone strategies, Nils Rydbeck, the chief technology officer of Ericsson, highlighted this unity with the analogy of "the melting pot", "[...] which basically meant future phones would be amalgams of several gadgets, such as cameras, computers, and music players" (Woyke 2014, 28).

As mobile devices with multimedia features that users can always carry with them, rather than external technological tools, smartphones have become devices holding a special place in their users' lives, as if they were a part of the natural environment around those users. This shift has withdrawn many other media tools from circulation or caused these other media tools to become insignificant (Deuze and The Janissary Collective 2012, 297-301). The convergence of smartphones with social media has given users an opportunity to be mobilised within both the physical and the virtual environment (Lee 2013, 272). This important factor varies smartphone usages.

As is well known, smartphones are important devices in reaching Web 2.0 services based on users' collective labour, especially social media. Firstly, social media includes "World Wide Web platforms such as social networking sites, blogs, wikis, and micro blogs" even though the term today refers only to social networking sites such as Facebook or Twitter (Fuchs 2013, 265). The 'social' side of social media stems from the features it enables such as "communication, community, cooperation, collaboration, and sharing" and, more importantly, the fact that these features are available for all online platforms (Fuchs 2013, 265). 
Because of this combination, smartphones are not only technological devices but also "social" devices, which have central importance in users' everyday lives, including a large variety of uses and meanings (Goggin 2009). As a result, some remarkable approaches have been developed recently on the axis of smartphones and users' social relations. As hybrid technologies, smartphones have begun to become defined structures such as polymedia or metamedia which emphasise their increasing importance in users' everyday lives, habits and social relations and also draw attention to environments of affordances and integration, as well as the smartphone itself as an object nesting various "constituent media" (Madianou and Miller 2012; Jensen 2013; Madianou 2014; Humphreys, Karnowski and von Pape 2018).

Offering these devices and services to people in commodity form is a vital phase in the transformation of everyday life on the axis of the capitalist mode of production. According to Manzerolle and Kjøsen $(2012,220)$, personalisation and ubiquitous connectivity are crucial features of digital media and, therefore the cycle of capital has become shorter than ever before. When considered from this general point of view, the social media activities of smartphone users and their personal data are of primary importance.

This study searches for the answers to the following research questions: In what ways has the emergence of social media and smartphones as a part of everyday life influenced 'leisure time' and the transformation of everyday life? How do users experience the character of the capitalist mode of production as it transforms everyday life through 'small' devices such as smartphones?

To answer the research questions, in-depth interviews were conducted with 30 smartphone users living in Ankara and Istanbul, both in Turkey, from May 2015 to February 2016. In parallel with the prevalence of smartphones, the focus was on the everyday experiences of users of different classes, genders, and ages, and on the users' opinions about these experiences. This study includes the experiences and ideas of 11 of the 30 interviewees who participated in my doctoral dissertation research. The interviews lasted from 45 minutes to two hours and comprised conversations around semi-structured questions where users could express their experiences freely.

The present article consists of two main sections focusing on the intersection of everyday life and smartphones in the context of commodification and relations of exploitation in the age of current digital capitalism. In the theoretical review, I focus on the literature dealing with smartphones, social media, and the transformation of everyday life in line with commodification, and the literature allowing us to understand this transformation. In Section 3, I bring together this literature with the real, daily experiences of Turkish smartphone users and demonstrate how these economic relations are experienced in the routine and ordinary use of these devices. In doing so, I will emphasise a facet to which the recent media studies focusing on social relations, usage patterns, and smartphones do not pay enough attention. Smartphone usages that are shaped in the axis of social relations should be considered together with the economic relations that show themselves as ordinary social relations or are hiding in the shadows of the latter.

\section{Theoretical Background: (Social) Media, Leisure Time and Exploitation}

Dallas W. Smythe's (1977) article, "Blindspot of Western Marxism", enables us to approach the relations between social media and the transformation of everyday life. According to Smythe $(1951 ; 2006)$, the main output of mass media is audience power, which is a fairly concrete output; the working principle of mass media, which on the 
surface is free for the audience, is based on the productive activity, exploitation, and commodification of the audience. Therefore, mass media is not, in fact, for free. The sustainability of the capitalist form of production is maintained through mass advertising. People sitting in front of the television are bought and sold between the advertisers and those who enable advertising as a commodity. According to Smythe, this exploitation is as real as it is indirect, is as based on myths (the myths of 'leisure time' and 'free') as it seems 'natural', and is hidden in the capillary vessels of everyday life; it simply occurs while watching television and listening to the radio.

The power of Smythe's theory is based on this argument, and the argument helps us to comprehend the present nature of digital media (Smythe 2006): the more the capitalist mode of production dominates the capillary vessels of society, the more "leisure time' turns into working time. The capitalist mode of production requires people to work to maintain their lives, except for a small minority who do not have to. The vast majority of people actually reproduce their labour force during the 'leisure time' that remains out of their paid working time and the time they spend on various responsibilities and needs (Pronovost 1998; Standing 2011; Rojek 1984). Therefore, 'leisure time' transforms into the extended of labour emerging in various forms. Due to this relation, domestic labour is also converted into the reproduction of the labour force (Vogel 2000). Finally, people do not escape the wheels of exploitation while sitting in front of mass media presentations as the audience or while preparing themselves for compulsory labour (Smythe 2006, 249-51).

All these are the results of a radical transformation in the mode of production; unlike the modes preceding capitalism, the reproduction of labour force in the capitalist mode of production matches with the consumption of commodities (Miller 2016). The producers in capitalist societies are obliged to satisfy their personal needs with the commodities they purchase from the market, rather than consuming the products they produce as they would have before capitalism (Rojek 1984). Ironically, the division of production and consumption through the market has resulted in ambiguity concerning the division between production and consumption. Michel de Certeau's words regarding "production, called "consumption'" define this process: "The latter is devious, it is dispersed, but it insinuates itself everywhere, silently and almost invisibly, because it does not manifest itself through its own products, but rather through its ways of using the products imposed by a dominant economic order" (de Certeau 1988, xii-xiii, emphasis mine).

The production that is realised through ways of using denotes the emergence of the phenomenon of people "who produce while consuming". Indeed, the term prosumer, composed by the combination of the concepts of producer and consumer and expressing the act of "outsourcing work to users and consumers, who work without payment", satisfies this need (Fuchs 2014, 99; Miller 2016). In many fast-food restaurants, gas stations, ATMs, online banking services, and within the entire scope of the service industry, the producers who are also described as consumers do various forms of work (also known as self-service) (Ritzer and Jurgenson 2010; Standing 2011, 121): "From this point of view, the dividing line no longer falls between work and leisure. These two areas of activity flow together. They repeat and reinforce each other" (de Certeau 1988, 29).

Today, audience labour is replaced with user labour (Fuchs 2013, 273), while many limitations such as the failure in the customisation of mass media and its dependence on location are handled through the features of digital technologies such as personalisation and ubiquitous connectivity (Manzerolle and Kjøsen 2012). The phenomenon of "digital labour" that has recently become popular and that we see also as free labour, 
immaterial labour or immaterial labour 2.0 defines this kind of transformation (Lazzarato 1996; Terranova 2013; Coté and Pybus 2007; Cohen 2008). Although digital labour cannot be reduced to social media or the productive activity of Web 2.0 users alone, it covers them all: "Digital labour is all paid and unpaid labour that helps creating digital technologies, content, and data that is sold as a commodity" (Fuchs 2016, 61). The emergence of a production and consumption relation also known as "Do-lt-Yourself culture" (Frissen 2015, 149), whose leading actors are amateur and ordinary users, implies the current ground of the transformation summarised above. In other words, as Italian Marxists have indicated on a larger scale, this transformation can be embraced as a process that is expressed through the inclusion of production in working time and 'leisure time', its extension over the whole of society, exceeding the factories, its acceptance as a means of social relation, and the transformation of society itself into a factory (social factory or society-factory) (Lazzarato 1996; Terranova 2013; Standing 2011, 38).

The commercialisation of Web 2.0 content, when compared to mass media, reveals significant differences. Firstly, prosumers play an active role when they use smartphones and share their personal data. For example, the main revenue of Facebook derives from broad information, including the content that users like, their friendship networks, the websites that they visit, the products that they purchase, and when and for how long they perform all these activities - and the users personally generate that information (Andrejevic 2015). When prosuming becomes a total social event, the exploitation-based character of the relation becomes more invisible (Cohen 2008, 7). Furthermore, since the products are not material but immaterial and seem to be a natural extension of social life, they are a process rather than a complete, stable product, and they are largely diversified and ephemeral rather than permanent; as a result of all these features, they are capable of pretending nonexistence even though they never disappear as a commodity (Terranova 2013). There is no discernible output of these activities for prosumers. Prosumption emerges as ways of using and the maintenance of social relations. It regenerates every hour, every day, and encompasses 'leisure time'. This activity is based on the exploitation of user labour and the commodification of their data.

\subsection{Everyday Life as Pseudoconcrete}

The methodological way to answer the research questions requires attention to the critical studies of everyday life. According to Lefebvre, science is rooted in everyday life (1991, 133): "In so far as the science of man exists, it finds its material in the 'trivial', the everyday. And it is the science of man - knowledge - which has blazed the trail for our consciousness". Even if the "trivial" sources of science have always existed, human knowledge discovered its own everyday roots only after the emergence of social sciences in the 19th century, and especially upon the birth of the tradition of the critical social sciences (Lefebvre 1971,12). The introduction of the capitalist mode of production within human life by creating "an immense collection of commodities", in Marx's own words $(1990,125)$, is critical to the emergence and rise of everyday life as a field of study.

To handle everyday life from this point of view also means conducting a discussion about essence and appearance because, rather than being manifested materially in everyday life, the "trivial" sources of science exist with many mediations and illusions. Kosik states that "The collection of phenomena that crowd the everyday environment and the routine atmosphere of human life, and which penetrate the consciousness of 
acting individuals with a regularity, immediacy, and self-evidence that lend them a semblance of autonomy and naturalness, constitutes the world of pseudoconcrete" (1976, 2). What makes everyday life pseudoconcrete arises because the real qualities of relations and things are often rendered invisible. Everyday life is a world of (i) external phenomena, (ii) manipulation, (iii) routine ideas, and (iv) fixed objects (Kosik 1976, 2).

However, why do people get misleading views of the world of objects in their everyday lives? This comprehensive question has to be narrowed down to our subject, commodification. In the first volume of Capital, when Marx examines the commodity form and "its mystical character", he states that in the market, the relations between producers are reduced to material relations, and these relations turn into social relations between things (commodities) $(1990,164-65)$. In these circumstances, the share of real producers is to adopt and keep pace with several given laws that seem to exist outside themselves. Thus, everyday life appears as an area where relations of production emerge as superhistorical relations between things (commodities) rather than as historical relations between people, and this formation is perceived as natural.

The transformation of what is a product of labour into commodities has two important implications for this study:

- Media in general, such as communication tools and social media, which are products of labour, have been transformed into commercial things on which exchangevalues are essential and are isolated from the use-values within those exchange relations (even if they still contain use-values for users).

- The quality of essentialness in the exchange relation reveals a medium of communication in which labour is invisible in everyday life, and this view is nothing but an illusion.

Everyday uses of things, including smartphones and social media, involve these relations in several ways. As we have seen, the most important social factor behind this is that smartphones and social media (with some rare exceptions such as Wikipedia) do not exist today except in commodity form. From this viewpoint, we can say that smartphones, technically defined as a "melting pot" (Woyke 2014, 28) and also defined as polymedia and metamedia in a broader sense (Madianou and Miller 2012; Jensen 2013; Madianou 2014; Humphreys, Karnowski and von Pape 2018), fit the intricate social relations into their small dimensions. We can analyse these social relations by examining ordinary aspects of everyday life.

Of course, the relations between smartphones and exploitation cannot be limited to the everyday experience of users. As Dyer-Witheford (2015, 102-123) has comprehensively pointed out, the subject of smartphones and exploitation includes "slave labour" to extract precious minerals like coltan, assembly lines of "bloody Taylorism" and all kinds of labour scattered around the world. On the other hand, the daily experiences of the 'end-user' require us to ask how these exploitative relations find their place in the capillary vessels of everyday life and how they affect the 'end-user' who seems to be free from these relations.

\section{The Transformation of Everyday Life through Smartphones}

Parallel to the diversity of user experiences, users' ideas about their own experiences can often contain elements that seem to be contradictory at first glance, and their comments can vary according to each different usage practice. However, there is a common point in their narratives: as expected, the everyday life of all smartphone users is 
shaped largely around the routine and ordinary use of these devices. This is the starting point for this study and the most crucial stratum of the uneven economic relations between users and social media companies.

\subsection{Routine, Ordinary and More: Being Exploited while "Not Doing Anything"}

To start with the most basic and ordinary aspects, we can first consider the statements of Soner (35, male), a worker in a pharmaceutical warehouse. Soner began by saying, "I am not getting up from my chair to pay a bill, thanks to the banking application; it has made things easier", and became less positive about smartphone use a little later: "Now we're more socialised. We share more. The guy shares his breakfast! Like, you know, you say this guy has cooked menemen. ${ }^{1}$ We know everything(!)"

Usually, the users' first contact with their smartphones starts from the moment they open their eyes in the morning when they close the alarm clock application. As soon as users wake up, they pick up their smartphones and connect to social networks, and they use their smartphones extensively during the day at home, at school, at work, on the street, on public transport, and even in toilets. What English teacher Ceyda (27, female) says sheds light on the everyday routine around a smartphone:

The very first thing I do in the morning is to look at the phone. I don't even say good morning to anybody. When I first get the phone, the first thing I do is to check my email, because I check if there is a job. After that, I go on Twitter. Then, I go on Facebook.

It is in my hand, in my pocket everywhere. I don't say 'I will put it somewhere and check it if it rings'. I put it in my pocket and it goes everywhere with me within the house. I am even going to the bathroom, I mean, with [the] phone. Such is the extent. I am not doing anything; I am checking Facebook, going to Twitter. I am watching the news. I look at the magazine a lot [emphasis mine].

Banu (30, female), a civil servant, gave another example, comparing the desktop computer and smartphone in terms of ease of use: "I almost never use my desktop computer at home; it is just there. The smartphone is much easier for me; it comes to the room I want, at home, at work. I use it even in the bathroom. This has replaced the reading of the newspaper in the bathroom". Similarly, Atalay (27, male), who sells second-hand phones, said: "The phone is in my hand half of the time I am awake during the day", and explained his relationship with his smartphone with the following: "As soon as I get up in the morning, I pick up the phone. I check Instagram first. Who did what at night, what the next day? Then I look at the football news, and if I have time, I read forums".

As can be seen, the users are "not doing anything" while navigating around social media. On the other hand, they deal with daily things, "pay bills", "receive news from friends" and "follow magazines" with their smartphones, carrying them like an extra limb. Their comments are positive or negative, depending on the type of use, and follow one after another. This chain of practices involving ordinary work and digital boredom tells us that smartphones "are anchored within and also anchor the daily rhythms and routines that constitute everyday life, removing boundaries between work and leisure, paid and unpaid work" (Hand 2016, 128). Prosuming is a direct result of these "remov[ed] boundaries". As these ordinary and routine everyday uses continue, users'

1 Turkish omelette. 
personal information is commodified and traded, and they produce and consume almost all the content of social media. Regardless of whether users notice all this, production and exploitation occur in everyday routines in a very insidious manner, without making themselves seen as a part of the ways of use and social relations at home, in the bathroom, at work, or at school.

Various everyday sources enable this relation to be maintained in this way. Two important determinations of Theodor W. Adorno and Max Horkheimer, focusing on mass media related to capitalism and entertainment, shed light on the aforementioned situation. According to Adorno and Horkheimer, "Entertainment is the prolongation of work under late capitalism. It is sought by those who want to escape the mechanized labour process so that they can cope with it again" $(2009,52)$. We do not examine mass media here, but just as Adorno and Horkheimer emphasise, users can use smartphones as an escape from the busy life and fatigue of the day: "People who are spent want to relax in 'play', often by watching a screen or conducting a dialogue with a series of screens" (Standing 2011, 128). Today, these screens are often those of smartphones.

Ahmet $(27$, male) identified a significant relation between people's intensive social media use and working life while explaining the reproduction of compulsory labour, 'leisure time' and labour force through media at home: "You come from work. You have four hours to spend at home, and you are either watching TV or navigating on social media, one or both. They are cheaper and also require less effort and less physical power than doing other things".

Banu (30, female), who does not want to leave the house on weekends, describes a similar situation: "For example, I'm not going anywhere or doing anything at the weekend. The TV is on in the living room. It sounds like someone's there. I have the phone in my hand. I go on Twitter all day".

This is consistent with the second relation between capitalism and entertainment that Adorno and Horkheimer determine: "[...] mechanization has such power over leisure and its happiness, determines so thoroughly the fabrication of entertainment commodities, that the off-duty worker can experience nothing but afterimages of the work process itself" $(2009,52)$. People coming from work find a device that offers 'free' services; in the evenings or at the weekends at home, they can watch various videos, like or share, while relieving the tiredness of that day's work and preparing themselves for the next day's work. Today, it is hard to find audiences who remain passive while watching the television and listening to the radio. It is quite usual to find an active prosumer trying to relieve the tiredness of the day on social media, where user data is commodified and 'leisure time' becomes an extension of working time.

At this point, a closer look at the use-value of smartphones is required. As mentioned earlier, use-value may differ in every single situation and for every single individual. As Marx notes, "the commodity is, first of all, an external object, a thing which through its qualities satisfies human needs of whatever kind. The nature of these needs, whether they arise, for example, from the stomach, or the imagination, makes no difference" $(1990,125)$. When these experiences are considered in terms of exchange-value, they appear as the economic equivalents of each use-value, whether or not this is noticed at first glance in everyday life. There is no doubt that people use smartphones for specific use-values, but the commodification of user data is generally related to the current functioning of the capitalist mode of production.

While, on the one hand, uneven economic relations that seem like social relations between individuals continue every day, on the other, users can gain genuinely emancipatory benefits from this 'social' device. One example of this is found in the Gezi Park 
protests in Turkey in June 2013. Of the 30 interviewees, 20 stated that they used their smartphones to access breaking news during the protests in order to avoid biased and falsified news from mainstream traditional media, and 13 interviewees actively participated in the anti-government protests and used their smartphones to communicate with other protesters, and to share pictures, videos and various other information. During the protests, smartphones gained some use-values such as accessing/producing real news, countering or resisting police violence and giving people many opportunities to spread the protests from a small park across the country, despite a mainstream media embargo and of course many other political factors (Walton 2015; Castells 2015, 227-30). This is to say that, whether political or not, each user may gain several usevalues via smartphones. This does not mean that the analysis of the political economy is invalid, but it shows the degree to which social relations can be multidimensional and how economic relations are hidden behind everyday social relations within the contemporary form of the capitalist mode of production.

\subsection{Commodification of Location: In Order to "Seem Social"}

Foursquare, a social media company that allows users to share the places they visit on the application Foursquare Swarm, with the slogan "Turn every day into a game", is a current and popular example of this capitalist mode of production that is increasingly spreading into everyday life and rising through gaming. This kind of locationbased application should be considered as within the game category, because through them users transform the city in which they live into a playground within the hustle of everyday life (Hjorth 2012; Gazzard 2011): "Foursquare and Gowalla include elements of gameplay where people can compete by scoring points for checking into different places" (de Souza e Silva and Frith 2015, 173). While users try to earn various points, through these applications "not only [do] goods and services become commodified, but also location" $(2015,174)$.

The commodification of the urban space through location-based applications occurs through the use of advertising by users in social networks (check-ins) and 'free' product or service offers by some commercial venues for check-ins. De Souza e Silva and Frith identify three important points about the commodification of space by users' check-ins: (i) ads are delivered to a very specific audience, (ii) ads are made directly by users, and (iii) ads are localised; as a result of these factors, advertising content becomes highly personal $(2015,174)$. Consequently, while users' social media activities become a new type of advertising activity, an inevitable identity is established between social media profiles and advertising content. It can be said that the secret of Foursquare's popularity is hidden in allowing users to present themselves as lifestyle images through a variety of companies and commercial spaces, and to do so in a game-like event.

Two things demonstrate that this is not a tightly held secret. Both companies and users are aware of the situation. It is not surprising that the companies are aware of it; it would be more surprising if they weren't. Companies that are trying to access various market data are concerned about creating and managing the above-mentioned trends for users; Foursquare is proud of responding to this request. ${ }^{3}$ Concurrently, users re-

2 "Foursquare Swarm". Available at: www.swarmapp.com (accessed 22 July 2017).

3 "Foursquare's location platform makes our tools and data available to leading brands and companies, helping them to locate, engage with, message and measure consumers". Available at: www.foursquare.com/about (accessed 13 March 2019). 
alise that they are doing some kind of advertising activity and constructing various images about themselves while transforming the everyday city into a playground. Of course, Foursquare is aware of that too. ${ }^{4}$

For university student Rüya (22, female), on the one hand, Foursquare Swarm has functional meanings for meeting friends, while on the other hand it complements the impression she wants to give about herself on social media. The fact that Rüya finds it ridiculous to check-in at the Akman Patisserie, which is generally preferred by middleaged and older people, and that she states that she likes to check-in at the Babel Pub, which is preferred by her age group, reveals the link between the image she wants to give about herself and the commercialisation on the platform.

Hüseyin (25, male), a construction worker, states that he checks in at Nata Vega (a shopping mall), in Kızllay (downtown of Ankara), or in venues in Konur Street (one of the cultural streets in Ankara that stands out with its alternative identity) when he comes from the countryside to the city, where he is mostly for business purposes, in order to "socialise" and "seem social". For Hüseyin, who lives in the countryside, Foursquare Swarm is a tool to get involved or appear to be involved in the social life of the city.

While all these occur in people's lives as various forms of use, another aspect of prosumption has emerged. Based on these examples, it can be said that, regardless of the purposes and the benefits of usage, location-based applications, whose content is created by users, incorporates everyday life more powerfully into the field of capital accumulation. Moreover, while all this relation is in the forms of games, entertainment, and image building, once again, the limits of exploitation encompass people's social relations; advertisements are made to voluntary users directly, and not only are the users commodified, but also the space in which they exist.

\subsection{Transformation of the Smartphone into a Work Tool: "It Can Happen in Our Work, Unfortunately"}

Another form of transformation of everyday life through smartphones is observed when paid work extends to 'leisure time'. This situation, as Sennett $(2014,64)$ states, should be considered as an outcome of the policies of flexibility, although it differs from the forms of outside-the-workspace flextime, which is widespread together with the development of computers and is often carried out via e-mail. As highlighted earlier, the shift of paid work to 'leisure time' should generally be seen as an outcome of the spread of production to society beyond the factories, and as a result of the ambiguity of the classical distinction between 'leisure time' and working time (Standing 2011, 118-19). In fact, this transformation, which we encounter regarding working practices, is unsurprising when the relation of capitalism with time is considered. One of the main focal points of the capitalist mode of production has been its control over time and its increasingly efficient use regarding surplus value generation (Booth 1991). The economic logic of capitalism generally demands acceleration in all areas of production and consumption (Rosa 2005). Therefore, it is necessary to mention an important contradiction between the transformation of the work in the axis of flexibilisation policies and labour power: "Work is physically decentralized, power over the worker is more direct. Working at home is the ultimate island of the new regime" (Sennett 2014, 6). In this sense, decentralisation of work - the first examples of which were also called telework along with ICTs (Ling and Haddon 2003) - involves the employment of employees in their 'leisure

4 "Location is more than a data point. We believe that the places you go say a lot about who you are". Available at: www.foursquare.com/about (accessed 4 June 2019). 
time' and the transformation of smartphones into work tools. The new forms of working through smartphones correspond to this new mode of work that Agger (2011) calls iTime, in which labour is increasingly being handled through informational services and with the flexibility created in time and space.

One of the most common examples of these devices turning into work tools is the provision of a second smartphone by companies to employees. Yeşim (26, female), who works in a small company providing consultancy services in the education sector, was given a smartphone by the company because she had to stay in touch with both her boss and her customers outside working hours. Yeşim, who uses two smartphones, one for business and one for personal purposes, explained the problem she encountered when the company phone stopped working: "My most urgent thing is to email teachers and talk on the phone. My boss started scolding me at work; 'your phone must never be off even outside working hours because there might be an emergency', etc. It can happen in our work, unfortunately. That's why he said that we shall buy a new phone if necessary".

Similarly, the statements of Illker (33, male), who works as an electrical engineer in a multinational company, are important in demonstrating the extent to which work can extend to 'leisure time'. Illker, who travels frequently for business in Turkey, is able to use Teamviewer during these trips, at home in the evenings, or in any other location, accessing the computer at work from his personal computer or smartphone. Teamviewer defines itself with the following: "Through innovations in technology and an incredibly fast and secure global network, we're making the world a smaller place paving the path towards a truly global workspace". ${ }^{5}$ The software brings together the aforementioned function, people, places, and objects, as in our example, on the work. This integration has no time and space limitation; in fact, precisely because it targets the overcoming of the time and space limitation, the boundary between working and 'leisure time' becomes more ambiguous than ever. However, Illker has stated that he tries to prevent the extension of work in 'leisure time' by turning the company phone off outside working hours and forwarding the incoming calls to his personal phone, not answering them if he does not recognise the number, and not checking e-mails. Yet not only through the smartphone, but also through the integration between the smartphone and the computer, an attempt to include 'leisure time' in working time can be observed.

By its very nature, journalism is among the occupational groups most closely related to the uncertainty of working hours. Nevertheless, the fact is that smartphones have increased the ambiguity between overtime and 'leisure time' in journalism. The working routine of Nazan (33, female), a national news channel's diplomatic reporter handling the Prime Ministry (prior to its abolition in 2017) and the Ministry of Foreign Affairs, highlighted the current picture in this respect. Nazan describes the work pace that has been shaped around the smartphone: "I check my emails as soon as I open my eyes. My emails are constantly open and I set them to be seen on the screen [of the smartphone]. I use WhatsApp secondly because we have a news group with the other reporters and editors in the company". WhatsApp groups with representatives, supervisors, news editors, and reporters in the Ankara office of the channel are always active: "There are times when I wake up from sleep. There are times when I am awakened by a call. I am always following the work at weekends and holidays".

In addition, Nazan states that she mostly uses the camera and WhatsApp on her smartphone for work. She uses these for one reason only: speed. She says that she

\footnotetext{
${ }^{5}$ Available at: www.teamviewer.com/ (accessed 14 May 2019).
} 
prefers to use WhatsApp to send and receive news photos and annotations to or from the news centre as quickly as possible. Through the smartphone's multimedia features, news text, photos, video calls, and voice recordings can be transferred via the same device at the same time, remaining open to the whole news team.

These user experiences illustrate how a personal communication tool becomes a business tool and how paid work extends to 'leisure time'. As we have seen, smartphones are highly functional in establishing communication as quickly as possible, in terms of business, in providing management-employee-customer relations as quickly as possible, and in handling work with multimedia possibilities (photos, written documents, video broadcasts, etc.) comprehensively and effectively. It has been shown that the transformation of smartphone into work tool and 'leisure time' into working time, as in other examples, occurs as part of everyday routines and within the framework of seemingly ordinary relations ('the necessity of work').

\section{Conclusion}

This study examines the means by which everyday life is transformed through smartphones, focusing on the daily experiences of smartphone users in Turkey, and searching for the answer to these main research questions: In what ways has the emergence of social media and smartphones as a part of everyday life influenced 'leisure time' and the transformation of everyday life? And how do users experience the character of the capitalist mode of production that transforms everyday life through 'small' devices such as smartphones?

First of all, despite the omissions in articles that evaluate smartphones as metamedia and polymedia but do not address the economic aspect of the transformation of everyday life (Madianou and Miller 2012; Jensen 2013; Madianou 2014; Humphreys, Karnowski and von Pape 2018), smartphone users, as they engage in the most common everyday uses, become the object of a series of economic relations that are embedded in social relations but do not present themselves as such at first glance. We can easily argue that a smartphone as a "melting pot of several gadgets" (Woyke 2014, 28) becomes a melting pot of exploitation, hosting many different types of the latter, as long as the smartphone exists in commodity form. All the gadgets with which smartphones are equipped, and the vast majority of applications that are accessed via smartphones, exist to increase capital accumulation. Simply put, through smartphones, companies can more easily reach users' personal information, including their photographs, locations and so on, for commercial purposes. On the other hand, users create most of the content on social media with their collective digital labour, and yet they do not get paid in any form. All this is in line with the three elements of exploitation of digital labour, as Fuchs (2012) terms it: users have to use commercial social media (coercion); companies, not users, own social media and its profit (alienation); and users lose their personal information to large companies (appropriation).

Therefore, users actually do a great deal in terms of capital accumulation while they are "not doing anything" at home with their smartphones. As they themselves reference from time to time, this "meaningless" activity is quite meaningful to capital as it entails the further deepening of exploitation. In relation to this, the more meaningless activity the smartphone users take part in from the moment they open their eyes in the morning until they sleep at night, the more meaningful the capital becomes. The more time prosumers spend on social media, the more they work for the accumulation of capital.

Moreover, all of this working practice is seen in everyday life as various forms of usage and social relations. This situation, which emerges in everyday life in terms of working practice, also sheds light on the dual relations between wandering around not 
doing anything and work that extends to 'leisure time'. Smartphone users experience this dual usage practice that we see in the same communication medium as idleness in the first case and more work in the latter. Even though it does not seem so in everyday life, this means that work is done in two different ways in 'leisure time' for an ordinary person, and it means that exploitation occurs in two different ways for capital as well. In other words, while smartphone users are exploited in two different ways in their 'leisure time', capital enriches its own value in two different ways.

As stated earlier, the theoretical discussions and field data of this study derived from a larger study which focused on Turkish smartphone users' everyday experiences and users' labour. Because the ordinary and everyday aspects of these relations may seem contradictory and contain a wide range of experiences, it is necessary to note that more comprehensive studies focusing on users' daily habits are needed. Broader field research in this respect can provide more extensive answers to the question of how the capitalist mode of production dominates the capillary vessels of society and how smartphone users experience that domination. In this sense, the differences between users of different classes, ages and genders, which are neglected, constitute the limitations of the study and should also be put within scope in further studies.

\section{References}

Adorno, Theodor W, and Max Horkheimer. 2009. The Culture Industry: Enlightenment as Mass Deception. In Media and Cultural Studies Key Works, edited by Meenakshi Gigi Durham and Kellner M. Douglas, 41-72. Oxford: Blackwell.

Agger, Ben. 2011. iTime: Labor and Life in a Smartphone Era. Time \& Society 20 (1). SAGE Publications Ltd: 119-36. doi:10.1177/0961463X10380730

Andrejevic, Mark. 2015. Personal Data: Blind Spot of the 'Affective Law of Value'? The Information Society 31 (1): 5-12. doi:10.1080/01972243.2015.977625

Booth, William James. 1991. Economies of Time: On the Idea of Time in Marx's Political Economy. Political Theory 19 (1): 7-27. http://www.jstor.org/stable/191731

Castells, Manuel. 2015. Networks of Outrage and Hopes: Social Movements in the Internet Age. Cambridge: Polity Press.

Cohen, Nichole S. 2008. The Valorization of Surveillance: Towards a Political Economy of Facebook. Democratic Communiqué 22 (1): 5-22.

Coté, Mark and Jennifer Pybus. 2007. Learning to Immaterial Labour 2.0: MySpace and Social Networks. Ephemera 7 (1): 88-106.

de Certeau, Michel. 1988. The Practice of Everyday Life. Translated by Steven Rendall. London: University of California Press.

de Souza e Silva, Adriana and Jordan Frith. 2015. "Location-Based Mobile Games:" In Playful Identities, edited by Valerie Frissen, Sybille Lammes, Michiel de Lange, Jos de Mul, and Joost Raessens, 169-80. The Ludification of Digital Media Cultures. Amsterdam University Press. http://www.jstor.org/stable/j.ctt14brqd4.12.

Deuze, Mark and the Jannisary Collective. 2012. Mobile Media Life. In Moving Data, edited by Pelle Snickars and Patrick Vonderau, 296-308. The IPhone and the Future of Media. Columbia University Press. http://www.jstor.org/stable/10.7312/snic15738.24

Dyer-Witheford, Nick. 2015. Cyber-Proletariat: Global Labour in the Digital Vortex. Toronto: Pluto Press.

Frissen, Valerie. 2015. Playing with Bits and Bytes: The Savage Mind in the Digital Age. In Playful Identities, edited by Valerie Frissen, Sybille Lammes, Michiel de Lange, Jos de Mul, and Joost Raessens, 149-64. The Ludification of Digital Media Cultures. Amsterdam University Press. http://www.jstor.org/stable/i.ctt14brad4.10

Fuchs, Christian. 2016. Critical Theory of Communication: New Readings of Lukács, Adorno, Marcuse, Honneth and Habermas in the Age of the Internet. London: University of Westminster Press. http://www.jstor.org/stable/j.ctv5vddf2 
Fuchs, Christian. 2014. Digital Labour and Karl Marx. New York: Routledge.

Fuchs, Christian. 2013. Class and Exploitation on the Internet. In Digital Labor: The Internet as Playground and Factory, edited by Trebor Scholz, 211-24. New York: Routledge.

Fuchs, Christian. 2012. Dallas Smythe Today: The Audience Commodity, the Digital Labour Debate, Marxist Political Economy and Critical Theory. Prolegomena to a Digital Labour Theory of Value. tripleC: Communication, Capitalism \& Critique 10 (2): 692-740.

Gazzard, Alison. 2011. Location, Location, Location: Collecting Space and Place in Mobile Media. Convergence 17 (4): 405-17. doi:10.1177/1354856511414344

Goggin, Gerard. 2009. Adapting the Mobile Phone: The iPhone and Its Consumption. Continuum 23 (2): 231-44. doi:10.1080/10304310802710546

Hand, Martin. 2016. \#Boredom: Technology, Acceleration, and Connected Presence in the Social Media Age. In Boredom Studies Reader, edited by Michael E. Gardiner and Julian Jason Haladyn, 155-129. New York: Routledge.

Hjorth, Larissa. 2012. Relocating the Mobile: A Case Study of Locative Media in Seoul, South Korea. Convergence 19 (2): 237-49. doi:10.1177/1354856512462360

Hsiao, Ming-Hsiung, and Liang-Chun Chen. 2015. Smart Phone Demand: An Empirical Study on the Relationships between Phone Handset, Internet Access and Mobile Services. Telematics and Informatics 32 (1): 158-68. https://doi.org/10.1016/..tele.2014.06.001

Humphreys, Lee, Veronika Karnowski, and Thilo von Pape. 2018. Smartphones as Metamedia: A Framework for Identifying the Niches Structuring Smartphone Use. International Journal of Communication 12: 2798-2809.

Jensen, Klaus Bruhn. 2013. How to Do Things with Data: Meta-Data, Meta-Media, and MetaCommunication. First Monday 18 (10). https://doi.org/10.5210/fm.v18i10.4870

Kosik, Karel. 1976. Dialectics of the Concrete. Translated by Karel Kovanda and James Schmidt. Dordrecht: D. Reidel.

Lazzarato, Maurizio. 1996. Immaterial Labour. In Radical Thought in Italy: A Potential Politics, edited by Paolo Virno and Michael Hardy. Minneapolis: University of Minnesota.

Lee, Dong-Hoo. 2013. Smartphones, Mobile Social Space, and New Sociality in Korea. Mobile Media \& Communication 1 (3): 269-84. doi:10.1177/2050157913486790

Lefebvre, Henri. 1991. Critique of Everyday Life [vol. 1]. Translated by John Moore. New York: Verso Books.

Lefebvre, Henri. 1971. Everyday Life in the Modern World. Translated by Sacha Rabinovitch. New York: Harper \& Row.

Ling, Rich and Leslie Haddon. 2003. Mobile Telephony, Mobility, and the Coordination of Everyday Life. In Machines That Become Us, edited by James E. Katz, 245-265. London: Transaction.

Madianou, Mirca. 2014. Smartphones as Polymedia. Journal of Computer-Mediated Communication 19 (3): 667-80. https://doi.org/10.1111/jcc4.12069

Madianou, Mirca, and Daniel Miller. 2012. Polymedia: Towards a New Theory of Digital Media in Interpersonal Communication. International Journal of Cultural Studies 16 (2): 16987. doi:10.1177/1367877912452486

Manzerolle, Vincent R. and Atle Mikkola Kjøsen. 2012. The Communication of Capital: Digital Media and the Logic of Acceleration. tripleC: Communication, Capitalism \& Critique 20 (1): 29-42. https://doi.org/10.31269/triplec.v10i2.412

Marx, Karl. 1990. Capital: A Critique of Political Economy [vol. 1]. Translated by Ben Fowkes. London: Penguin Books.

Miller, Toby. 2016. Cybertarian Flexibility: When Prosumers Join the Cognitariat, All That Is Scholarship Melts into Air. In Precarious Creativity: Global Media, Local Labor, edited by Michael Curtin and Kevin Sanson, 19-32. Oakland: University of California Press. doi:10.1525/9780520964808-004

Pronovost, Gilles. 1998. Leisure Time. Current Sociology 46 (3): 71-82. doi:10.1177/0011392198046003009

Ritzer, George and Nathan Jurgenson. 2010. Production, Consumption, Prosumption: The 
Nature of Capitalism in the Age of the Digital 'Prosumer.' Journal of Consumer Culture 10 (1): 13-36. doi:10.1177/1469540509354673

Rojek, Chris. 1984. Did Marx Have a Theory of Leisure? Leisure Studies 3 (2): 163-74. doi:10.1080/02614368400390141

Rosa, Hartmut. 2005. The Speed of Global Flows and the Pace of Democratic Politics. New Political Science 27 (4): 445-59. doi:10.1080/07393140500370907

Sennett, Richard. 2014. Karakter Aşınması [The Corrosion of Character: The Personal Consequences of Work in the New Capitalism]. Translated by Barış Yıldırım. İstanbul: Ayrıntı.

Smythe, Dallas W. 2006. On the Audience Commodity and Its Work. In Media and Cultural Studies Key Works, edited by Meenakshi Gigi Durham and Douglas M. Kellner, 230-56. Oxford: Blackwell.

Smythe, Dallas W. 1977. Communications: Blindspot of Western Marxism. Canadian Journal of Political and Social Theory 1 (3): 1-27.

Smythe, Dallas W. 1951. The Consumer's Stake in Radio and Television. The Quarterly of Film Radio and Television 6 (2): 109-128. doi:10.2307/1209898

Standing, Guy. 2011. The Precariat: The New Dangerous Class. New York: Bloomsbury.

Terranova, Tiziana. 2013. Free Labor. In Digital Labor: The Internet as Playground and Factory, edited by Trebor Scholz, 46-77. New York: Routledge.

Vogel, Lise. 2000. Domestic Labor Revisited. Science \& Society 64 (2): 151-70. http://www.jstor.org/stable/40403837

Walton, Jeremy F. 2015. 'Everyday I'm Çapulling!'. Global Flows and Local Frictions of Gezi. In Everywhere Taksim: Sowing the Seeds for a New Turkey at Gezi, edited by Isabel David and Kumru F. Toktamis, 45-58. Amsterdam: Amsterdam University Press. doi:10.1515/9789048526390-005

Woyke, Elizabeth. 2014. The Smartphone: Anatomy of an Industry. New York: The New Press.

\section{About the Author}

\section{Emre Canpolat}

Emre Canpolat works as a research assistant at Hacettepe University, Faculty of Communication, Ankara. He obtained his PhD degree from Ankara University Graduate School of Social Sciences in 2017 with a dissertation on alienation, commodity fetishism and smartphones. His academic interests include political economy of media, new media, digital labour, and globalisation. He has been the assistant editor of Moment Journal since 2018. 